tourniquet. Conf Proc IEEE Eng Med Biol Soc. 2011; 2011:3776-9.

10. Friesen RH, Honda AT, Thieme RE. Changes in anterior fontanel pressure in preterm neonates during tracheal intubation. Anesth Analg. 1987; 66(9):874-8.

11. Pokela ML, Koivisto M. Physiological changes, plasma betaendorphin and cortisol responses to tracheal intubation in neonates. Acta Paediatr. 1994; 83(2):151-6.
12. Dargaville PA, Aiyappan A, De Paoli AG, Kuschel CA, et al. Minimally-invasive surfactant therapy in preterm infants on continuous positive airway pressure. Arch Dis Child Fetal Neonatal Ed. 2013; 98(2):F122-6.

13. Alexandre C, De Jonckheere J, Rakza T, Mur S, et al. Impact du cocooning et de la voix humaine sur le systéme nerveux autonome (SNA) del'enfant grand prématuré. Arch Pediatr. 2013; 20(9):963-8.

\title{
Child's respiratory and sleep health following mid-trimester amniocentesis
}

\author{
Danielius Serapinas, Prof. MD PhD ${ }^{a, b}$ and Daiva Bartkeviciene, Assoc Prof MD PhD. ${ }^{c}$
}

\begin{abstract}
Objective. The aim was to investigate the rates of respiratory and sleep disturbances in infants whose mothers experienced amniocentesis.

Material and methods. Infants whose mothers have undergone midterm amniocentesis (between 16 and 20 weeks) and no invasive procedure (controls) were enrolled.

Results. The study analyzed 50 infants whose mothers have undergone amniocentesis (amniocentesis group) and 47 controls. Amniocentesis group had higher incidence of sleep disturbances: 30 cases $(60 \%)$, compared with 11 controls $(23.4 \%)$ $(P=0.001)$. In the amniocentesis group there were 7 children (14\%) with asthma, while in the control group, asthma was confirmed in 1 child $(2.1 \%)(\mathrm{P}=0.032)$.

Conclusion. Our data triggers the hypothesis that associations between midterm amniocentesis, child's asthma and sleep disturbances may exist. These preliminary results reveal the importance of further studies and the need for the analysis of long term effects of invasive testing.

Key words: amniocentesis, informed consent, respiratory tract diseases, sleep disorders, infant.
\end{abstract}

http: / / dx.doi.org/10.5546/ aap.2019.eng.401

a. Department of Family Medicine, Medical Academy, Lithuanian University of Health Sciences, Kaunas, Lithuania.

b. Mykolas Romeris University, Vilnius, Lithuania.

c. Department of Obstetrics and Gynaecology, Faculty of Medicine, Vilnius University, Vilnius, Lithuania.

E-mail address:

Dr. Danielius Serapinas: dserapinas@gmail.com

Funding: None.

Conflict of interest: None.

Received: 9-9-2018

Accepted: 7-4-2019
To cite: Serapinas D and Bartkeviciene D. Child's respiratory and sleep health following mid-trimester amniocentesis. Arch Argent Pediatr 2019;117(6):401-404.

\section{INTRODUCTION}

The tendency of modern community to give birth at more advanced age conditioned that prenatal diagnostics methods became more frequently used in women's health care. Amniocentesis, a second trimester invasive test, is performed to detect chromosomal numeral and structural anomalies. ${ }^{1}$ However, despite their high sensitivity for detection rates, these procedures have their complication rates for the fetus and mother, including the fetal fluid embolism. ${ }^{2}$ The risks for fetus include not only miscarriage, with the excess risk of around 0.5-1\% above the background risk, ${ }^{3}$ but also there is a well-proved relationship between early amniocentesis and congenital anomaly (talipes). ${ }^{4}$ Despite these rare morphological consequences of amniocentesis, more frequent functional effects may occur that can have long-lasting consequences on a child's health and are not always observable at prenatal and perinatal stages. ${ }^{5}$ Functionally, the fetal lungs are extremely sensitive to the external mechanical effects. There are studies suggesting that respiratory disturbances such as neonatal pneumonia, meconium aspiration, atelectasis and tachypnea were more frequently found in the amniocentesis group. ${ }^{6-7}$ However, over the last 10 years, no studies were performed on the analysis of genetic amniocentesis and fetal respiratory health. Therefore, the present study aimed to investigate the rates of respiratory and sleep disturbances in children whose mothers experienced prenatal amniocentesis. 


\section{MATERIALS AND METHODS Study design}

The study was conducted in the period between 2014 and 2017. Infants whose mothers have undergone midterm amniocentesis and no antenatal invasive procedure were enrolled into the study if they had no respiratory problems at perinatal period. Amniocentesis over the period between 16 and 20 weeks was performed at Lithuanian University of Health Sciences and Vilnius University Hospital. The study was retrospective. The health state medical documentation of pregnant women who have been counselled by geneticist 3 years ago were analyzed. Inclusion criteria for research group: increased risk for fetal chromosomal anomalies (due to age risk or positive biochemical screening), performed invasive diagnostic testing at second trimester of pregnancy, no perinatal infections, no respiratory problems at perinatal period, no prenatal smoking history, no maternal asthma, no preterm delivery.

Inclusion criteria for control group were the same, only despite that they not performed invasive diagnostic testing (rejected by the women).

The maternal survey was performed when the infants were 3 years of age. Their mothers had undergone the second trimester amniocentesis for fetal karyotyping because of the advanced maternal age, high risk results of biochemical screening or family history of chromosomal abnormality. The data were compared with children whose mothers declined the test (the control group). The controls were counselled by the same geneticist, at the same time period and indications for invasive diagnostics were the same as research group. But controls declined invasive testing because of anxiety of possible complications including miscarriage.

The mothers were contacted by residency physician 3 years after delivery to access the results of children health status. The survey included questions about the confirmed child's diagnosis of asthma and events of bronchiolitis. In the absence of lung function tests, the diagnosis of asthma was considered with frequent ( $\geq 8$ days / month) asthma-like symptoms (according to Canadian Thoracic Society Asthma Clinical Assembly partnered with the Canadian Paediatric Society position paper on the diagnosis and management of asthma in preschoolers). ${ }^{8}$ Sleeping habits were evaluated according to Brief Infant Sleep Questionnaire (BISQ). ${ }^{9}$ Sleep disturbances were considered if a child reportedly wakes up $>3$ times per night, spends $>1$ hour in wakefulness during the night, or spends $<9$ hours in sleep (day and night). ${ }^{9}$ The study was approved by Kaunas Regional Bioethics Committee. Informed consent from all participants was taken.

\section{Statistical analysis}

The statistical analysis was performed using the SPSS 20.0 program. Quantitative variables were expressed as means with standard deviations (SD). The differences among means were analyzed for their statistical significance with the Mann-Whitney U or Chi square test. A $p$ value of less than 0.05 was considered significant.

\section{RESULTS}

Totally we invited 117 mothers, who had indications of amniocentesis, to participate in the study. 12 were excluded because of detected possible prenatal inflammatory state $(n=9)$ and

TABLE 1. Maternal and infants characteristics expressed as median or $n(\%)$

\begin{tabular}{|c|c|c|c|}
\hline Characteristics & $\begin{array}{l}\text { Midterm amniocentesis } \\
\qquad \mathrm{N}=50\end{array}$ & $\begin{array}{l}\text { Controls } \\
\mathrm{N}=47\end{array}$ & $p$ value \\
\hline Maternal age (years) & $37 \pm 3.8$ & $36.2 \pm 3.5$ & $p=0.21$ \\
\hline Maternal smoking & - & - & - \\
\hline Gestational age & $40.1 \pm 2.9$ & $39.7 \pm 2.3$ & $p=0.64$ \\
\hline Caesarian section & $5(10 \%)$ & $4(8.4 \%)$ & $p=0.24$ \\
\hline Birth weight & $3.36 \pm 0.4$ & $3.42 \pm 0.33$ & $p=0.53$ \\
\hline Male gender & $28(56 \%)$ & $20(42.5 \%)$ & $p=0.069$ \\
\hline Bronchiolitis & $2(4 \%)$ & $1(2.1 \%)$ & $p=0.11$ \\
\hline Asthma & $7(14 \%)$ & $1(2.1 \%)$ & $p=0.032$ \\
\hline Sleep disturbances & $30(60 \%)$ & $11(23.4 \%)$ & $p=0.001$ \\
\hline
\end{tabular}


impact of prenatal smoking $(n=3) .8$ mothers were eliminated from the study, because later on they refused to participate in the study. Finally 97 mothers with indications of amniocentesis were included in the analysis. Final data obtained from infants whose mothers have undergone midterm amniocentesis $(n=50)$ or no antenatal invasive procedure (controls, $\mathrm{n}=47$ ) are reported in Table 1 .

There were no differences in bronchiolitis rate between the groups $(p<0.05)$. However, we detected that asthma diagnosis and sleep disturbances were more frequent in the amniocentesis group compared with the controls $(\mathrm{p}<0.05)($ Table 1$)$.

\section{DISCUSSION}

The findings of the present study suggest that there are increased rates of asthma in children born to mothers subsequent to midterm amniocentesis. Our data support the results of other studies which showed that midterm amniocentesis may affect the fetal lung development, ${ }^{7}$ including the reduced vital capacity of crying in neonates. ${ }^{6}$ In small children, the crying vital capacity is one of the tests indicating the lung function. ${ }^{10} \mathrm{~A}$ causal relationship between maternal amniocentesis and the lung function deficit may have several mechanisms. At first, the lost amount of fetal fluids may matter because during midterm amniocentesis about $10-20 \mathrm{ml}$ of fetal fluids are removed, which is a rather large amount from the total of $130-160 \mathrm{ml}$ as estimated at 16 weeks of pregnancy. ${ }^{6}$ There are also data suggesting the need of lowering the amount of the removed fetal fluids in order to reduce fetal complication rates. ${ }^{1}$ It was estimated that by only removing $7 \mathrm{ml}$ of amniotic fluid instead of $15 \mathrm{ml}$, a total miscarriage rate, incidence of respiratory difficulties and fixed flexion deformities is decreased. ${ }^{11}$ The second mechanism may be that the process of amniocentesis itself may cause the reduction of fetal movements, including breathing which especially manifests 24-48 hours after amniocentesis. ${ }^{12}$ The reduction of fetal movements after chorionic villus sampling (CVS) or early amniocentesis is a well-known factor for other fetal malformations like tapes equinovarus. ${ }^{4}$ It is noteworthy that in animal models some histological changes in the lungs occurred regardless of the time of amniocentesis, the amount of fluid removed and even if the membranes were simply punctured with no fluid removal. ${ }^{13}$
The relationship between amniocentesis and the increased level of stress is well documented. ${ }^{14}$ During stress, the increased maternal cortisol level may pass through placenta and cause fetal hypothalamus-hypophysis-adrenal activation accompanied by long-lasting modifications in stress reactivity. ${ }^{14}$ The findings obtained in our study showed that suspected sleep disturbances more frequently observed in the amniocentesis group can also be connected with prenatal stress effects. There are data suggesting that prenatal stress exposure is connected with predisposition to a vulnerability to hyperarousal reactions contributing to insomnia even in adult life. ${ }^{15}$ Of course we can't exclude other possibly not detected reasons for observed children sleep disturbances.

After a prolonged pause in scholarly studies examining the link of invasive testing and fetal respiratory health, the results of our study remind the fact that amniocentesis may be associated with unwanted long-term effects on the child. These data point the need to look for the ways of reducing the numbers of invasive procedures. NIPT (non-invasive prenatal tests) tests may even decline the need of invasive testing. ${ }^{1}$

Our study has some limitations, for example, we have not performed the regression analysis to exclude other possible contributing factors. Also, the number of studied patients is low for the definite conclusions to be drawn. Annually 1000 invasive prenatal procedures are performed in Lithuania. Our cohort represents $5 \%$ of total amount. Taking into account all these data, every pregnant woman should be provided with a clear explanation of the differences of the prenatal care methods and before giving the informed consent, should be familiarized with the invasive procedure, including long term effects of the child's health. ${ }^{1}$ We also highlight the need for an informed patient consent before genetic amniocentesis and the benefit of receiving adequate information on possible alternatives of invasive testing.

\section{CONCLUSION}

Our data triggers the hypothesis that associations between midterm amniocentesis, child's asthma and sleep disturbances may exist. These preliminary results reveal the importance of further studies and the need for the analysis of long term effects of invasive testing. 


\section{REFERENCES}

1. Gray KJ, Wilkins-Haug LE. Have we done our last amniocentesis? Updates on cell-free DNA for Down syndrome screening. Pediatr Radiol. 2018; 48(4):461-70.

2. Drukker L, Sela HY, Ioscovich A, Samueloff A, GrisaruGranovsky S. Amniotic Fluid Embolism: A Rare Complication of Second-Trimester Amniocentesis. Fetal Diagn Ther. 2017; 42(1):77-80.

3. Seeds JW. Diagnostic mid trimester amniocentesis: how safe? Am J Obstet Gynecol. 2004; 191(2):607-15.

4. Alfirevic Z, Navaratnam K, Mujezinovic F. Amniocentesis and chorionic villus sampling for prenatal diagnosis. Cochrane Database Syst Rev. 2017; 9:CD003252.

5. Greenough A, Yuksel B, Naik S, Cheeseman P, Nicolaides KH. First trimester invasive procedures: effects on symptom status and lung volume in very young children. Pediatr Pulmonol. 1997; 24(6):415-22.

6. Vyas H, Milner AD, Hopkin IE. Amniocentesis and fetal lung development. Arch Dis Child. 1982; 57(8):627-8.

7. Yüksel B, Greenough A, Naik S, Cheeseman P, Nicolaides $\mathrm{KH}$. Perinatal lung function and invasive antenatal procedures. Thorax. 1997; 52(2):181-4.

8. Ducharme FM, Dell SD, Radhakrishnan D, Grad RM, et al.
Diagnosis and management of asthma in preschoolers: A Canadian Thoracic Society and Canadian Paediatric Society position paper. Paediatr Child Health. 2015; 20(7):353-71.

9. Sadeh A. A Brief Screening Questionnaire for Infant Sleep Problems: Validation and Findings for an Internet Sample. Pediatrics. 2004; 113(6):e570-7.

10. Carlsen K-H. Lung function during infancy and preschool age. Breathe. 2010; 6(3):221-6.

11. Gezer C, EkinA, Goynumer G, Pakay K, et al. Comparison of adverse perinatal outcomes after single-needle and doubleneedle CVS techniques. J Perinat Med. 2017; 45(2):199-203.

12. Manning FA, Platt LD, Lemay M. Effect of amniocentesis on fetal breathing movements. Br Med J. 1977; 2(6102):1582-3.

13. Hislop A, Howard S, Fairweather DV. Morphometric studies on the structural development of the lung in Macaca fascicularis during fetal and postnatal life. J Anat. 1984; 138(Pt 1):95-112.

14. McGowan PO, Matthews SG. Prenatal Stress, Glucocorticoids, and Developmental Programming of the Stress Response. Endocrinology. 2018; 159(1):69-82.

15. Palagini L, Drake CL, Gehrman P, Meerlo P, Riemann D. Early-life origin of adult insomnia: does prenatal-earlylife stress play a role? Sleep Med. 2015; 16(4):446-56. 